\title{
Should beta-blocker therapy be reduced or withdrawn after an episode of decompensated heart failure? Results from COMET is
}

\author{
Marco Metra $^{\mathrm{a}, *}$, Christian Torp-Pedersen ${ }^{\mathrm{b}}$, John G.F. Cleland ${ }^{\mathrm{c}}$, Andrea Di Lenarda ${ }^{\mathrm{d}}$, \\ Michel Komajda ${ }^{\mathrm{e}}$, Willem J. Remme ${ }^{\mathrm{f}}$, Livio Dei Cas ${ }^{\mathrm{a}}$, Philip Spark ${ }^{\mathrm{g}}$, \\ Karl Swedberg ${ }^{\text {h }}$, Philip A. Poole-Wilson ${ }^{\mathrm{i}}$ \\ for the COMET investigators ${ }^{1}$
${ }^{a}$ Section of Cardiovascular diseases; Department of Experimental and Applied Medicine, University of Brescia, Italy
${ }^{\mathrm{b}}$ Department of Cardiology, Bispebjerg University Hospital, Copenhagen, Denmark
${ }^{\mathrm{c}}$ Department of Cardiology, University of Hull, Kingston upon Hull, UK
d Department of Cardiology, Ospedale di Cattinara, Trieste, Italy
e Department of Cardiology, La Pitié-Salpétrière Hospital, Paris, France
${ }^{\mathrm{f}}$ Sticares Cardiovascular Research Foundation, Rhoon, The Netherlands
${ }^{g}$ Nottingham Clinical Research Group, Nottingham, UK
${ }^{\mathrm{i}}$ National Heart and Lung Institute, Imperial College London, UK \\ ${ }^{\mathrm{h}}$ Department of Emergency and Cardiovascular Medicine, Sahlgrenska Academy, Göteborg University, Göteborg, Sweden
}

Received 30 December 2005; received in revised form 4 February 2007; accepted 16 May 2007

Available online 19 June 2007

\begin{abstract}
Background: It is unclear whether beta-blocker therapy should be reduced or withdrawn in patients who develop acute decompensated heart failure (HF). We studied the relationship between changes in beta-blocker dose and outcome in patients surviving a HF hospitalisation in COMET.

Methods: Patients hospitalised for HF were subdivided on the basis of the beta-blocker dose administered at the visit following hospitalisation, compared to that administered before.

Results: In COMET, $752 / 3029$ patients $(25 \%, 361$ carvedilol and 391 metoprolol) had a non-fatal HF hospitalisation while on study treatment. Of these, 61 patients $(8 \%)$ had beta-blocker treatment withdrawn, $162(22 \%)$ had a dose reduction and $529(70 \%)$ were maintained on the same dose. One-and two-year cumulative mortality rates were $28.7 \%$ and $44.6 \%$ for patients withdrawn from study medication, $37.4 \%$ and $51.4 \%$ for those with a reduced dosage (n.s.) and $19.1 \%$ and $32.5 \%$ for those maintained on the same dose (HR, $1.59 ; 95 \%$ CI, $1.28-1.98$; $p<0.001$, compared to the others). The result remained significant in a multivariable model: (HR, $1.30 ; 95 \% \mathrm{CI}, 1.02-1.66 ; p=0.0318)$. No interaction with the beneficial effects of carvedilol, compared to metoprolol, on outcome was observed $(p=0.8436)$.

Conclusions: HF hospitalisations are associated with a high subsequent mortality. The risk of death is higher in patients who discontinue betablocker therapy or have their dose reduced. The increase in mortality is only partially explained by the worse prognostic profile of these patients. (C) 2007 European Society of Cardiology. Published by Elsevier B.V.
\end{abstract}

Keywords: Decompensated heart failure; Trials; Beta-blockers

\footnotetext{
Source of funding: COMET was supported by F Hoffmann La Roche and GlaxoSmithKline.

* Corresponding author. Cattedra di Cardiologia, c/o Spedali Civili, P.zza Spedali Civili, 25123 Brescia, Italy. Tel.: +39 030 3995572; fax: +39 030 3700359 .

E-mail address: metramarco@libero.it (M. Metra).

${ }^{1}$ The COMET investigators are listed in a previous paper (1).
}

\section{Introduction}

Randomised clinical trials have shown the beneficial effects of beta-blockers in the treatment of patients with relatively stable, symptomatic chronic heart failure (HF) due to left ventricular (LV) systolic dysfunction [1-6]. Despite 


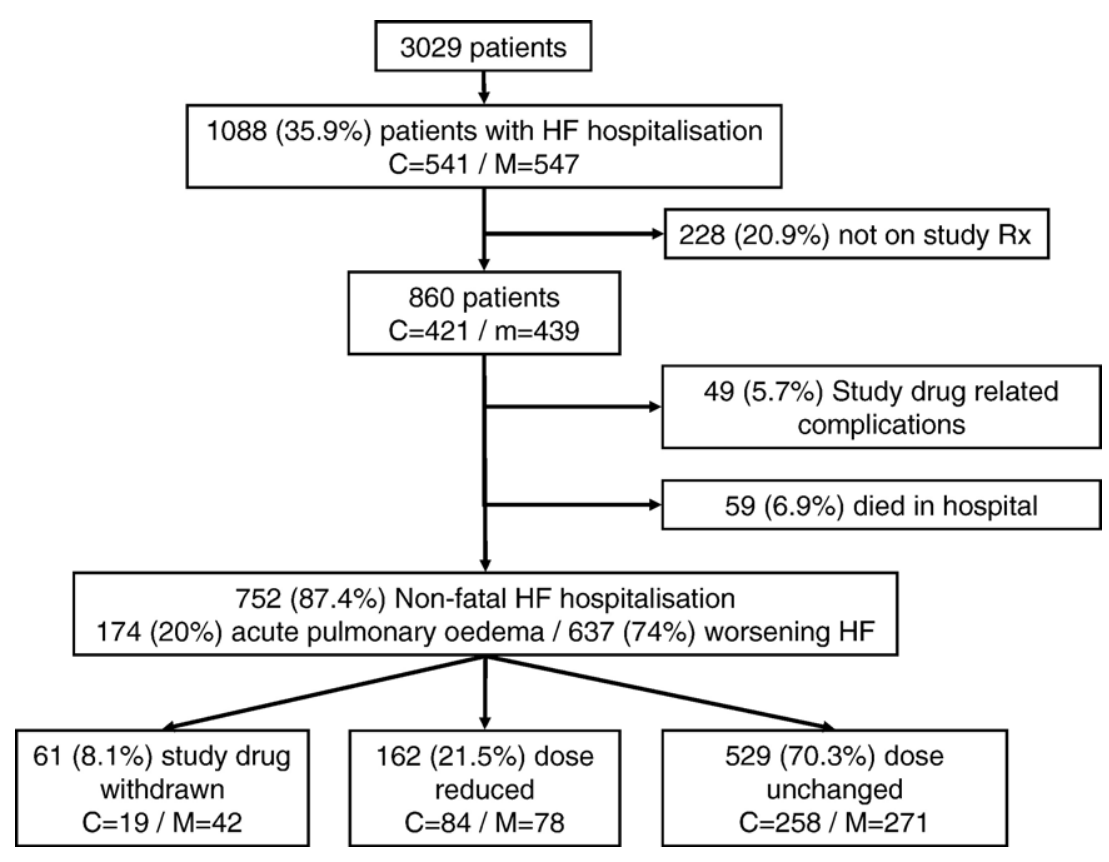

Fig. 1. Flow chart showing number of patients, follow-up and changes in study drug dosages for patients hospitalised for heart failure in COMET. Abbreviations: $\mathrm{C}=$ carvedilol; $\mathrm{M}=$ metoprolol; $\mathrm{HF}=$ heart failure.

the benefits of medical treatment many patients progress to advanced HF and are hospitalised for HF decompensation. When this occurs, beta-blockers are often reduced or discontinued [7-9] as it is thought that this will improve worsening dyspnoea, fatigue and/or hypotension, which may be exacerbated by the short-term negative inotropic effects of beta-blockade $[10,11]$. On the other hand, randomised controlled trials have shown that the beneficial effects of beta-blockers also occur among patients with severe HF. [2,12-15] Randomised trials, however, include selected patient populations. Even the patients included in the Carvedilol Prospective Randomized Cumulative Survival Study (COPERNICUS) had to be clinically stable with no need of i.v. therapy for at least 4 days before randomisation. We therefore have no definitive results about the effects of beta-blocker therapy on outcome in patients who have been recently hospitalised for decompensated HF.

In the Carvedilol or Metoprolol European Trial (COMET), 3029 patients with chronic HF were randomised to carvedilol or metoprolol tartrate and followed up for a median of 58 months [16]. This trial represents a unique possibility to assess the effects on outcome of a change in beta-blocker therapy after an episode of HF hospitalisation. In the present study we assessed the prognostic role of a change in the beta-blocker dose after a HF hospitalisation in the COMET patients.

\section{Methods}

The COMET design has been published [16,17]. In brief, COMET was a multicenter, randomised, double-blind, parallel-group trial comparing the effect on mortality and mor- bidity of carvedilol and metoprolol tartrate in patients with symptomatic chronic HF (NYHA class II-IV), LV ejection fraction $(\mathrm{EF}) \leq 35 \%$, at least one cardiovascular hospitalisation during the 2 years before trial entry, optimal baseline therapy, including the need for diuretic therapy. COMET was designed as an event-driven study with the co-primary endpoints of all-cause mortality and the combined endpoint of mortality or hospitalisation for any cause. Patients were randomised to carvedilol or metoprolol tartrate and received initial doses of $3.125 \mathrm{mg}$ or $5 \mathrm{mg}$ twice daily (bid) respectively. Doses were doubled at 2 week intervals, aiming for target doses of $25 \mathrm{mg}$ bid of carvedilol and $50 \mathrm{mg}$ bid of metoprolol tartrate. When patients reached the target or the maximally tolerated dose, the maintenance phase began. During this phase, every patient underwent clinical assessment every 4 months.

Hospitalisations were defined as any admission that required at least one overnight stay in the hospital $[17,18]$. The causes of admission were classified by the investigator on the case report form. Hospitalisations were differentiated as cardiovascular or non-cardiovascular. Causes of cardiovascular hospitalisations included HF, unstable angina, suspected myocardial infarction, stroke, or others. Three clinical presentations of HF hospitalisations were considered: worsening HF, acute pulmonary oedema and complications of drug treatment. Since this last category included only a few events (49 patients, 5.7\%), unrelated to HF (hypotension, dizziness, bradycardia), we excluded them from data analysis.

To assess the prognostic significance of the change in the beta-blocker dose after a HF hospitalisation, we compared the dose of beta-blocker administered at the visit following 
Table 1

Baseline characteristics of COMET patients hospitalised for heart failure according to changes in study drug doses

\begin{tabular}{|c|c|c|c|c|}
\hline & $\begin{array}{l}\text { All } \\
n=752\end{array}$ & $\begin{array}{l}\text { Withdrawn or reduced } \\
n=223\end{array}$ & $\begin{array}{l}\text { Unchanged } \\
n=529\end{array}$ & $\begin{array}{l}p \text { value withdrawn or reduced } \\
\text { versus unchanged }\end{array}$ \\
\hline Age (years) & $64 \pm 11$ & $65 \pm 10$ & $64 \pm 11$ & 0.278 \\
\hline Sex $(\%$ male $)$ & 76 & 70 & 78 & 0.025 \\
\hline Race (\% white) & 99 & 99 & 99 & 0.635 \\
\hline $\begin{array}{l}\text { Body Mass Index } \\
\left(\mathrm{kg} / \mathrm{m}^{2}\right)\end{array}$ & $27 \pm 4$ & $26 \pm 4$ & $27 \pm 5$ & 0.220 \\
\hline Systolic BP (mm Hg). & $124 \pm 20$ & $122 \pm 20$ & $124 \pm 20$ & 0.062 \\
\hline Diastolic BP (mm Hg) & $76 \pm 11$ & $75 \pm 11$ & $76 \pm 11$ & 0.445 \\
\hline Heart rate (bpm) & $81 \pm 13$ & $83 \pm 13$ & $81 \pm 13$ & 0.111 \\
\hline \multicolumn{5}{|l|}{ NYHA class $(\%)$} \\
\hline II & 40 & 32 & 42 & 0.035 \\
\hline III & 56 & 63 & 53 & \\
\hline IV & 6 & 5 & 6 & \\
\hline $\begin{array}{l}\text { Duration CHF (months) } \\
\text { mean/median }\end{array}$ & $51 / 32$ & $53 / 30$ & $51 / 32$ & 0.574 \\
\hline \multicolumn{5}{|l|}{ Aetiology $(\%)$} \\
\hline Ischaemic heart disease & 60 & 58 & 60 & 0.608 \\
\hline Hypertension & 18 & 13 & 20 & 0.032 \\
\hline Dilated cardiomyopathy & 39 & 39 & 39 & 0.908 \\
\hline Previous valve surgery & 4 & 2 & 4 & 0.197 \\
\hline LV ejection fraction (\%) & $25.1 \pm 7.2$ & $24.1 \pm 7.0$ & $25.5 \pm 7.3$ & 0.018 \\
\hline $\begin{array}{l}\text { NT-proBNP } \\
\quad(\mathrm{pg} / \mathrm{ml}) \text { median }\end{array}$ & 1890 & 2280 & 1771 & 0.797 \\
\hline \multicolumn{5}{|l|}{ Associated diagnosis (\%) } \\
\hline $\begin{array}{l}\text { Previous myocardial } \\
\text { infarction }\end{array}$ & 48 & 49 & 48 & 0.948 \\
\hline CAD (by angiography) & 65 & 67 & 64 & 0.470 \\
\hline Current angina & 25 & 21 & 27 & 0.070 \\
\hline Hypertension & 39 & 38 & 39 & 0.711 \\
\hline Diabetes & 33 & 33 & 32 & 0.800 \\
\hline Stroke & 9 & 8 & 9 & 0.763 \\
\hline \multicolumn{5}{|l|}{ ECG findings (\%) } \\
\hline Sinus rhythm & 71 & 69 & 72 & 0.294 \\
\hline Atrial fibrillation/flutter & 22 & 23 & 21 & 0.554 \\
\hline Paced rhythm & 8 & 9 & 8 & 0.563 \\
\hline$\%$ LBBB & 6 & 7 & 6 & 0.651 \\
\hline \multicolumn{5}{|c|}{ Concomitant medications (\%) } \\
\hline Diuretics & 99 & 99 & 99 & 0.623 \\
\hline ACE Inhibitors & 91 & 89 & 92 & 0.150 \\
\hline ARBs & 6 & 6.7 & 5.7 & 0.577 \\
\hline Digitalis & 62 & 66 & 60 & 0.097 \\
\hline Antiarrhythmics & 14 & 17 & 12 & 0.083 \\
\hline Nitrates & 39 & 35 & 41 & 0.010 \\
\hline Aldosterone antagonists & 14 & 17 & 13 & 0.154 \\
\hline Beta-blockers & 5 & 4 & 5 & 0.408 \\
\hline Anticoagulants & 48 & 46 & 49 & 0.367 \\
\hline Aspirin & 38 & 38 & 38 & 0.975 \\
\hline Statins & 21 & 18 & 23 & 0.172 \\
\hline
\end{tabular}

Abbreviations: $\%=$ percentage of patients; $\mathrm{BP}=$ blood pressure; $\mathrm{CAD}=$ coronary artery disease; $\mathrm{CHF}=$ heart failure; $\mathrm{LV}=$ left ventricular; $\mathrm{LBBB}=$ left bundle branch block; $\mathrm{ARBs}=$ angiotensin receptor blockers; $\mathrm{BB}=$ beta-blockers; $\mathrm{HR}=$ heart rate. Beta-blockers refer to patients receiving beta-blockers before entry into the trial.

the HF hospitalisation with the dose administered at the visit before the HF hospitalisation. Patients were subdivided in three groups: those who received the same dose before and after the HF hospitalisation; those who had a dose reduction of at least one level at the visit after the hospitalisation; and those who were withdrawn from the study drug. Dose levels were the following: $3.125 \mathrm{mg}$ bid, $6.25 \mathrm{mg}$ bid, $12.5 \mathrm{mg}$ bid, and $25 \mathrm{mg}$ bid for carvedilol, and $5 \mathrm{mg}$ bid, $12.5 \mathrm{mg}$ bid, $25 \mathrm{mg}$ bid, and $50 \mathrm{mg}$ bid for metoprolol.

\subsection{Statistical analysis}

Results are expressed as mean \pm SD unless otherwise specified. All hypothesis tests reported are two-sided and use a $p$ value $<0.05$ as significant. Differences were assessed by t-tests for continuous variables and by chi-squared test for categorical data. Kaplan-Meier survival estimates were calculated.

To assess the impact of the change in beta-blocker dose on mortality after the HF hospitalisation, changes in the beta- 
Table 2

Clinical characteristics of the patients at the visit before the heart failure hospitalisation according to changes in study drug doses

\begin{tabular}{|c|c|c|c|c|}
\hline & $\begin{array}{l}\text { All } \\
n=752\end{array}$ & $\begin{array}{l}\text { Withdrawn or reduced dose } \\
n=223\end{array}$ & $\begin{array}{l}\text { Unchanged } \\
n=529\end{array}$ & $\begin{array}{l}p \text { value withdrawn or reduced } \\
\text { versus unchanged }\end{array}$ \\
\hline NYHA class (\%) & & & & 0.044 \\
\hline I & 5 & 3 & 6 & \\
\hline II & 39 & 34 & 41 & \\
\hline III & 46 & 53 & 43 & \\
\hline IV & 9 & 9 & 9 & \\
\hline Orthopnoea (\%) & 23 & 29 & 21 & 0.014 \\
\hline Dyspnoea (\%) & & & & 0.317 \\
\hline Asymptomatic & 8 & 7 & 9 & \\
\hline Walking upstairs & 31 & 28 & 31 & \\
\hline Walking normally & 32 & 32 & 32 & \\
\hline Walking slowly & 21 & 26 & 19 & \\
\hline At rest & 8 & 7 & 8 & \\
\hline Angina (\%) & & & & 0.483 \\
\hline Yes & 18 & 15 & 19 & \\
\hline No & 82 & 85 & 81 & \\
\hline Well being (\%) & & & & 0.039 \\
\hline Very good & 4 & 4 & 4 & \\
\hline Good & 28 & 21 & 31 & \\
\hline Average & 35 & 41 & 33 & \\
\hline Poor & 23 & 23 & 24 & \\
\hline Very poor & 9 & 11 & 8 & \\
\hline Pulmonary rales (\%) & 17 & 16 & 18 & 0.504 \\
\hline Peripheral oedema (\%) & & & & 0.315 \\
\hline Yes & 24 & 21 & 25 & \\
\hline No & 76 & 79 & 75 & \\
\hline Body weight, $\mathrm{kg}$ & $79 \pm 16$ & $76 \pm 15$ & $80 \pm 16$ & 0.006 \\
\hline Systolic blood pressure, $\mathrm{mm} \mathrm{Hg}$ & $122 \pm 21$ & $118 \pm 21$ & $124 \pm 21$ & 0.001 \\
\hline Diastolic blood pressure, $\mathrm{mm} \mathrm{Hg}$ & $75 \pm 11$ & $74 \pm 12$ & $75 \pm 11$ & 0.653 \\
\hline Study drug dose, $(\%)$ & & & & 0.008 \\
\hline C, $3.125 \mathrm{mg}$ bid, M $5 \mathrm{mg}$ bid & 18 & 13 & 20 & \\
\hline C, $6.25 \mathrm{mg}$ bid; $\mathrm{M} 12.5 \mathrm{mg}$ bid & 17 & 18 & 16 & \\
\hline C, $12.5 \mathrm{mg}$ bid; M $25 \mathrm{mg}$ bid & 16 & 22 & 13 & \\
\hline C, $25 \mathrm{mg}$ bid; M $50 \mathrm{mg}$ bid & 48 & 45 & 49 & \\
\hline Days from randomisation to hospitalisation (\%) & & & & 0.338 \\
\hline $0-74$ & 23 & 20 & 25 & \\
\hline $75-385$ & 25 & 28 & 24 & \\
\hline $386-926$ & 25 & 27 & 25 & \\
\hline$>926$ & 26 & 25 & 26 & \\
\hline
\end{tabular}

blocker dose were included in a multivariable Cox regression model including baseline factors, shown to be important by bootstrap methods, as well as variables collected at the visit before the hospitalisation and causes of hospitalisation that differed significantly between the beta-blocker dose groups. The baseline variables included in the model are those retained in $\geq 70 \%$ of the models generated by backward regression from 200 bootstrap samples of the patients in the study, i.e. random samples of 3029 patients with replacement. No data are available regarding patients' symptoms and treatment during the HF hospitalisation. The variables entered into the multivariable model were: age, sex, systolic blood pressure, NYHA class, HF duration, LVEF, serum creatinine, sodium, and haemoglobin levels, cardiac rhythm (sinus, paced, atrial fibrillation), furosemide dose, administration of antiarrhythmics, digitalis, lipid lowering agents, study drug, amongst the variables assessed at baseline; body weight, systolic blood pressure, NYHA class, orthopnoea, well being, study drug dose level, amongst the variables assessed at the visit prior to the HF hospitalisation; acute pulmonary oedema, and worsening HF, amongst the causes of the hospitalisation; and, finally, study drug dose change or withdrawal.

The adjusted mortality curves in Fig. 3B are produced from the survivor function of the multivariate Cox regression analysis. The beta-blocker dose variable (reduced/withdrawn versus same dose) is a stratified variable, which results in separately shaped curves (i.e. non-proportional for each).

\section{Results}

\subsection{Follow-up}

In COMET, 3029 patients were randomised to carvedilol (1511 patients) or metoprolol tartrate (1518 patients) and followed for a median of 58 months (interquartile range 54 to 
Table 3

Reasons for admission and precipitating factors causing heart failure hospitalisation

\begin{tabular}{|c|c|c|c|c|}
\hline & Withdrawn & Reduced dose & Same dose & $p$ value \\
\hline & $N=61$ & $N=162$ & $N=529$ & \\
\hline \multicolumn{5}{|l|}{ Reason for admission } \\
\hline $\begin{array}{l}\text { Acute pulmonary } \\
\text { oedema }(\%)\end{array}$ & 36.1 & 20.4 & 13.6 & $<0.001$ \\
\hline Progressive WHF (\%) & 78.7 & 85.2 & 89.8 & 0.021 \\
\hline \multicolumn{5}{|c|}{ Cause of WHF hospitalisation } \\
\hline Ischaemia (\%) & 16.4 & 19.8 & 17.2 & 0.730 \\
\hline Atrial fibrillation (\%) & 14.8 & 18.5 & 11.3 & 0.057 \\
\hline Infection $(\%)$ & 3.3 & 10.5 & 10.6 & 0.191 \\
\hline Non-compliance $(\%)$ & 4.9 & 6.2 & 4.5 & 0.702 \\
\hline Renal dysfunction (\%) & 9.8 & 5.6 & 4.9 & 0.276 \\
\hline Other $(\%)$ & 44.3 & 47.5 & 49.0 & 0.768 \\
\hline Alcohol excess (\%) & 1.6 & 0.0 & 0.6 & 0.318 \\
\hline Dietary salt excess (\%) & 3.3 & 5.6 & 3.6 & 0.513 \\
\hline Hypertension (\%) & 3.3 & 5.6 & 5.3 & 0.775 \\
\hline Iatrogenic $(\%)$ & 11.5 & 5.6 & 5.9 & 0.211 \\
\hline
\end{tabular}

More than one causes could be adjudicated. Abbreviations: WHF $=$ worsening heart failure.

64). Follow-up was complete for all patients except 5 who were lost to follow-up and 28 patients who withdrew their consent during the trial [16]. Patient flow is shown in Fig. 1. Amongst the 3029 patients included in COMET, 1088 (35.9\%, 541 on carvedilol and 547 on metoprolol) were hospitalised for HF. Of these, 228 patients (20.9\%) were excluded from analysis as they were not on study medication at the time of hospitalisation. The cause of the HF hospitalisation of the remaining 860 patients (421 on carvedilol and 439 on metoprolol) was adjudicated as acute pulmonary oedema, worsening HF and study drug related complications in $174(20 \%)$, $637(74 \%)$ and $49(6 \%)$ patients, respectively. Fifty-nine patients $(7 \%)$ died during the initial hospitalisation.
Further analysis is limited to the 752 patients who had a non-fatal HF hospitalisation caused by acute pulmonary oedema or worsening HF. Amongst them, 61 patients (8.1\%, 19 on carvedilol and 42 on metoprolol) were withdrawn from their study medication, $162(21.5 \%, 84$ on carvedilol and 78 on metoprolol) had a reduction in their study drug dose, and 529 (70.3\%, 258 on carvedilol and 271 on metoprolol) were maintained on the same study drug dose at the visit following the HF hospitalisation, compared to before. Overall, patients receiving carvedilol were less likely to be withdrawn from study medication or have a dose reduction, compared to those on metoprolol $(p=0.018)$.

\subsection{Clinical characteristics.}

The characteristics of the patients' hospitalised for HF, subdivided on the basis of changes in their beta-blocker dose, are shown in Tables 1 and 2. Since there were no differences between patients withdrawn from study medication and those who had the dose reduced, these two groups are shown together. At baseline, the patients withdrawn from study medication or who had a dose reduction were less likely to be males, had more severe symptoms (NYHA class) and more severe LV systolic dysfunction (LVEF), compared to those who had their beta-blocker dose unchanged (Table 1). At the visit prior to the HF hospitalisation, patients withdrawn from study drug treatment or who reduced their beta-blocker dose had more severe symptoms (NYHA class), a higher prevalence of orthopnoea, poorer well being, a lower body weight and a lower systolic blood pressure.

The duration of the initial hospitalisation was longer in the patients who were withdrawn or had a dose reduction, compared to the others: $27 \pm 53$ days; median, interquartile range (IQR), 17, 7-28 days in those withdrawn, $11 \pm 9$ days,

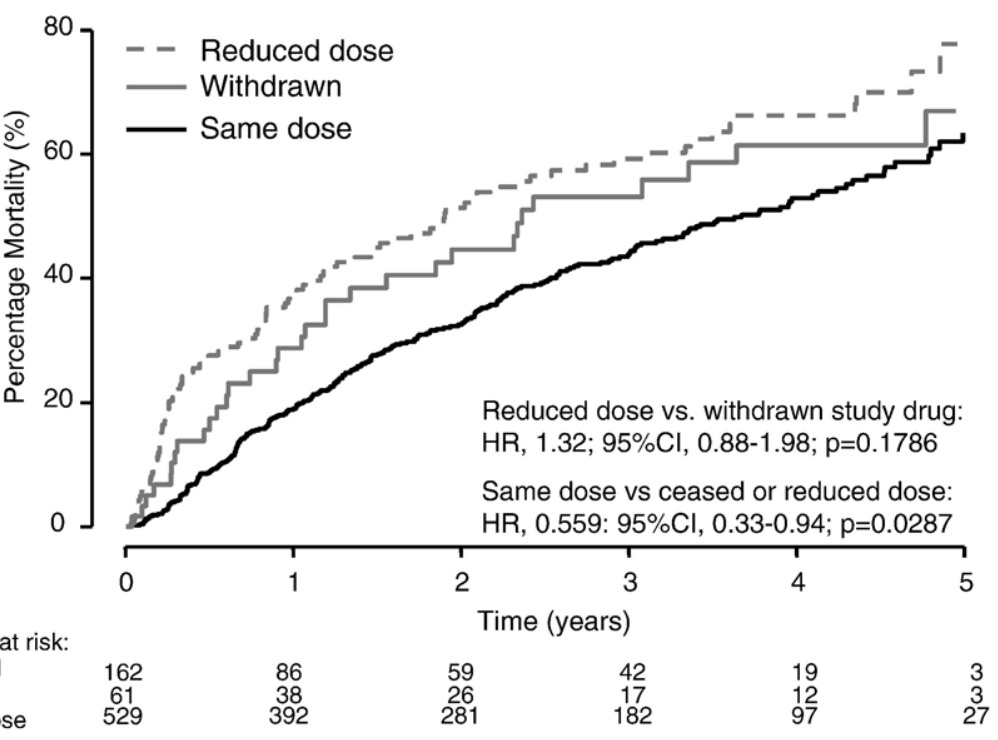

Fig. 2. Kaplan-Meier curves of mortality subsequent to discharge for the patients who had an admission for HF, according to whether study medication was withdrawn, the dose was dose reduced or the dose was left unchanged (same dose). 
Table 4

Variables predictive of all cause mortality post heart failure hospitalisation at multivariable analysis

\begin{tabular}{lrlr}
\hline & HR & \multicolumn{1}{l}{$95 \%$ CI } & \multicolumn{1}{l}{$p$} \\
\hline Baseline variables & & & \\
Increasing age (years) & 1.035 & $1.022-1.048$ & $<0.0001$ \\
Female versus male & 0.749 & $0.558-1.006$ & 0.0548 \\
Increasing HF duration (months) & 1.003 & $1.001-1.005$ & 0.0006 \\
Increasing LVEF & 0.975 & $0.959-0.99$ & 0.0017 \\
Increasing serum creatinine $(\mu \mathrm{mol} / \mathrm{L})$ & 1.003 & $1.001-1.004$ & 0.0002 \\
Increasing serum sodium $(\mathrm{mmol} / \mathrm{L})$ & 0.974 & $0.948-1.000$ & 0.0504 \\
ECG: sinus rhythm versus paced & 1.436 & $0.991-2.08$ & 0.0558 \\
Diuretic dose $81-160$ versus $\leq 40 \mathrm{mg} /$ day & 1.591 & $1.163-2.178$ & 0.0037 \\
Diuretic dose $161-320$ versus $\leq 40 \mathrm{mg} /$ day & 1.457 & $0.945-2.246$ & 0.0885 \\
Antiarrhythmics & 1.671 & $1.217-2.296$ & 0.0015 \\
Digitalis & 1.816 & $1.416-2.328$ & $<0.0001$ \\
Lipid lowering medication & 0.593 & $0.435-0.808$ & 0.0009
\end{tabular}

Prior to hospitalisation

Increasing systolic blood pressure $(\mathrm{mm} \mathrm{Hg}) \quad 0.984 \quad 0.977-0.991 \quad<0.0001$

Study drug (beta-blocker) dose change

Reduced/withdrawn versus same dose $\quad 1.302 \quad 1.023-1.656 \quad 0.0318$

median, IQR, 8, 5-14 days in those with dose reduction versus $9 \pm 8$ days, median, IQR, 7, 4-12 days in those with dose unchanged ( $p<0.0001$ versus the others).

The potential causes and precipitating factors of the HF hospitalisations are shown in Table 3. Patients withdrawn from beta-blocker therapy and, to a lesser extent, those who had a reduction in their beta-blocker dose were more likely to be admitted because of acute pulmonary oedema rather than because of progressive HF. The precipitating factors for HF hospitalisation did not differ amongst groups.

\subsection{Mortality versus changes in beta-blocker dose}

Hospitalisation for HF was associated with high mortality. Mortality was not different between the patients withdrawn from beta-blocker therapy and those who had a dose reduction. Thirty-two of the 61 patients $(52.5 \%)$ withdrawn from the study drug died and 94 of the 162 patients $(58 \%)$ who had a dose reduction also died (hazard ratio $=1.32 ; 95 \%$ confidence intervals [CI], $0.88-1.98 ; p=0.179$ ). These two groups were therefore combined for the purposes of comparison with patients maintained on the same dose of study drug, of whom 242 of 529 died (45.7\%; HR, 1.59; $95 \%$ CI, 1.28-1.98; $p<0.0001$ for the comparison) (Fig. 2).

Patients who were maintained on the same dose of the study medication had less severe HF compared to those who had a dose reduction or who were withdrawn. However, their mortality risk remained lower after adjustment for baseline variables and variables collected at the visit before the HF hospitalisation (HR, 1.30; 95\% CI, 1.02-1.66; $p=0.0318$; Table 4 and Fig. 3). The other variables which were associated with increased mortality after the HF hospitalisation at multivariable analysis were increasing age, higher serum creatinine, greater HF duration, lower serum sodium, lower LVEF, treatment with higher furosemide doses, antiarrhythmic therapy, digitalis therapy, lack of use of statins, lower systolic blood pressure at the visit prior to hospitalisation (Table 4).

To address the sensitivity of the analyses to high risk patients, they were repeated disregarding patients that died within 4 weeks of hospitalisation (8 patients). The risk of subsequent mortality remained higher in those patients that reduced or withdrew study medication compared to those that were maintained on the same dose $(\mathrm{HR}, 1.51 ; 95 \% \mathrm{CI}$, $1.22-1.89 ; p<0.001)$ but an adjusted analysis resulted in a non-significant difference between these groups (HR, 1.25; 95\%CI, 0.98-1.60; $p=0.0711$, Table 5).

The mortality rate after hospitalisation in each group was lower amongst the patients receiving carvedilol, compared to those on metoprolol (data not shown). No interaction between the changes in dose after the HF hospitalisation and the

\section{A Mortality following discharge}

\section{B Mortality following discharge} (adjusted for other variables)
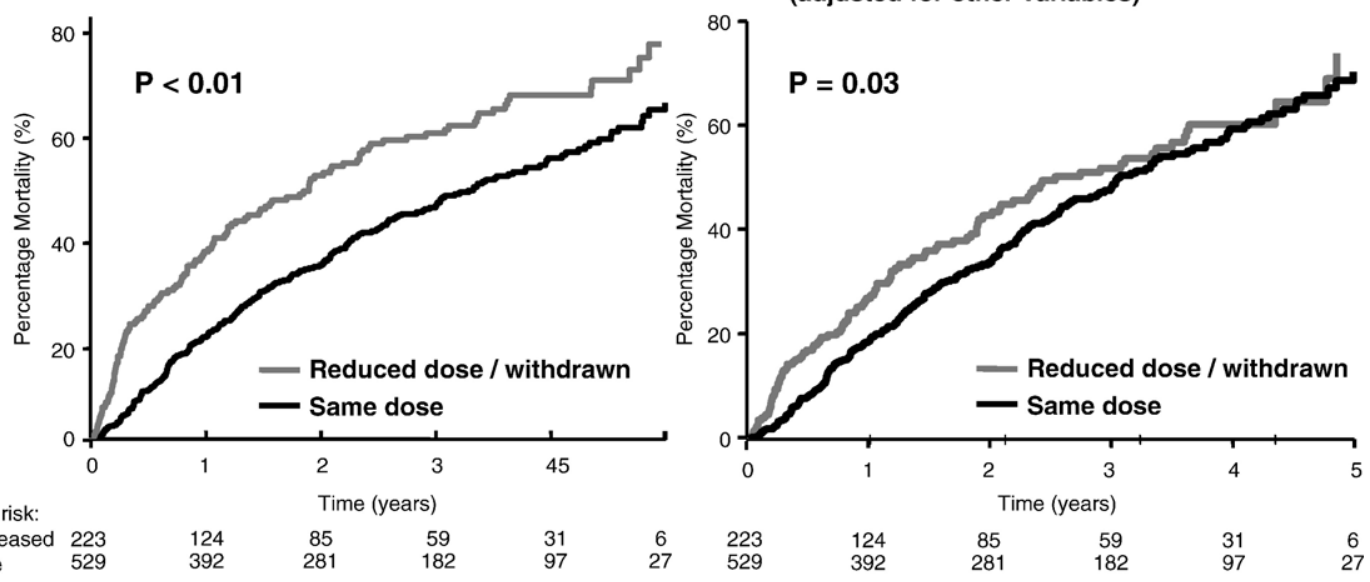

Fig. 3. Kaplan-Meier mortality curves for the patients withdrawn from study medication or who had the dose reduced compared to those who had no dose change. Mortality curves were unadjusted (3A) or adjusted (3B) for other variables related to mortality at multivariable analysis. 
Table 5

Variables predictive of all cause mortality post heart failure hospitalisation at multivariable analysis after excluding subjects who died within 4 weeks of admission

\begin{tabular}{|c|c|c|c|}
\hline Baseline variables & HR & $\begin{array}{l}95 \% \\
\mathrm{CI}\end{array}$ & $p$ \\
\hline $\begin{array}{l}\text { Increasing age } \\
\text { (years) }\end{array}$ & 1.035 & $\begin{array}{l}1.022, \\
1.048\end{array}$ & $<0.0001$ \\
\hline $\begin{array}{l}\text { Female versus } \\
\text { male }\end{array}$ & 0.764 & $\begin{array}{l}0.568 \\
1.028\end{array}$ & 0.0758 \\
\hline $\begin{array}{l}\text { Increasing HF } \\
\text { duration (months) }\end{array}$ & 1.003 & $\begin{array}{l}1.001 \\
1.005\end{array}$ & 0.0006 \\
\hline Increasing LVEF & 0.973 & $\begin{array}{l}0.958 \\
0.989\end{array}$ & 0.0009 \\
\hline $\begin{array}{l}\text { Increasing serum } \\
\text { creatinine }(\mu \mathrm{mol} / \mathrm{L})\end{array}$ & 1.003 & $\begin{array}{l}1.001 \\
1.005\end{array}$ & 0.0001 \\
\hline $\begin{array}{l}\text { Increasing serum } \\
\text { sodium }(\mathrm{mmol} / \mathrm{L})\end{array}$ & 0.973 & $\begin{array}{l}0.947 \\
1.000\end{array}$ & 0.0468 \\
\hline $\begin{array}{l}\text { ECG: sinus rhythm } \\
\text { versus paced }\end{array}$ & 1.468 & $\begin{array}{l}1.008 \\
2.137\end{array}$ & 0.0451 \\
\hline $\begin{array}{l}\text { Diuretic dose } 81-160 \\
\text { versus } \leq 40 \mathrm{mg} / \text { day }\end{array}$ & 1.576 & $\begin{array}{l}1.15 \\
2.161\end{array}$ & 0.0047 \\
\hline Antiarrhythmics & 1.627 & $\begin{array}{l}1.178 \\
2.249\end{array}$ & 0.0032 \\
\hline Digitalis & 1.859 & $\begin{array}{l}1.447 \\
2.39\end{array}$ & $<0.0001$ \\
\hline $\begin{array}{l}\text { Lipid lowering } \\
\text { medication }\end{array}$ & 0.593 & $\begin{array}{l}0.434 \\
0.811\end{array}$ & 0.0011 \\
\hline \multicolumn{4}{|l|}{ Prior to hospitalisation } \\
\hline $\begin{array}{l}\text { Increasing systolic } \\
\text { blood pressure }(\mathrm{mm} \mathrm{Hg})\end{array}$ & 0.984 & $\begin{array}{l}0.977 \\
0.991\end{array}$ & $<0.0001$ \\
\hline \multicolumn{4}{|l|}{$\begin{array}{l}\text { Study drug (beta-blocker) } \\
\text { dose change }\end{array}$} \\
\hline $\begin{array}{l}\text { Reduced/withdrawn } \\
\text { versus same dose }\end{array}$ & 1.253 & $\begin{array}{l}0.981 \\
1.601\end{array}$ & 0.0711 \\
\hline
\end{tabular}

beneficial effect on mortality of carvedilol, compared to metoprolol, was found ( $p=0.8436)$.

\section{Discussion}

\subsection{Background and previous studies}

Lack of prescription and use of low doses of beta-blockers may adversely affect the outcome of HF patients [19-22]. However, the prognostic significance of a dose reduction and/or withdrawal of beta-blocker therapy may differ in the patients recently hospitalised for worsening HF. In these patients, beta-blockade may theoretically have adverse effects on outcome because of its short-term negative inotropic effects. $[10,11]$ Accordingly, symptoms of worsening HF and low cardiac output (weight gain, fatigue, hypotension) are amongst the most common reasons of discontinuation of beta-blocker therapy in clinical practice $[7,8,23,24]$. However, there is little information on the impact of changes in beta-blocker therapy after hospitalisation for worsening HF. A retrospective analysis of the Outcomes of the Prospective Trial of Intravenous Milrinone for Exacerbations of Chronic
Heart Failure (OPTIME-CHF) study [25] reported that, amongst 212 patients treated with beta-blockers at the time of the admission for decompensated HF, the 47 patients who permanently stopped the beta-blocker had a worse outcome [25]. The 268 of 432 patients receiving beta-blockers at the time of hospitalisation in the Evaluation Study of Congestive Heart Failure and Pulmonary Artery Catheterization (ESCAPE) had a shorter length of stay and lower 6-month mortality rate and beta-blocker therapy remained independently associated with lower mortality at multivariable analysis [26]. The Organized Program to Initiate Lifesaving Treatment in Hospitalized patients with Heart Failure (OPTIMIZE-HF) showed that carvedilol use at the time of discharge after a HF hospitalisation is well tolerated and associated with a reduction in mortality at 60 and 90 days. [27].

\subsection{Beta-blocker withdrawal or dose change in the present study}

COMET is one of the largest and longest trials of patients with chronic HF on optimal medical treatment. This, therefore, allows an assessment of the relation between the changes in beta-blocker treatment and subsequent outcome. Our results show that either discontinuation or a reduction in the dose of the beta-blocker after a HF hospitalisation is associated with a worse outcome. Though stopping betablockers or reducing their dose was associated with more severe HF, it remained significantly and independently associated with increased mortality after adjustment for baseline variables and for variables obtained at the visit before the HF hospitalisation. Our results are consistent with recent analyses from trials [25,27] and registries $[20,26]$ and show, in addition, that even a reduction in the beta-blocker dose may be associated with an increase in mortality.

When the patients who died in the first 4 weeks after the initial hospitalisation were excluded, discontinuation or dose reduction in beta-blockers remained associated with increased mortality at univariable but not multivariable analysis $(p=0.0711)$. These results show the role of changes in beta-blocker therapy for short-term outcome. The lower significance of dose changes at multivariable analysis may be explained by the reduction in the number of events so that the power of the model to detect significant changes was reduced as well.

We did not find any difference in outcome between the patients who had beta-blocker therapy withdrawn and those who had a dose reduction. This may reflect the relatively low number of patients who were completely withdrawn from beta-blocker therapy (61 patients, $8 \%$ ). On the other hand, the association between reduction in beta-blocker dose and adverse outcome is consistent with post-hoc analysis of this and other trials $[19,21,22]$. However, no trial has adequately, prospectively assessed whether the dose of beta-blocker has an important effect on clinical outcome. 


\subsection{Carvedilol versus metoprolol tartrate comparison}

The COMET trial showed that carvedilol administration is associated with a lower mortality, compared to metoprolol tartrate, in patients with HF. Carvedilol did not reduce the rate of HF hospitalisation, compared to metoprolol, but its effect on mortality was observed whether or not such a hospitalisation had occurred. Our present study shows that patients assigned to carvedilol were less likely to be withdrawn from beta-blockade or have a reduction in their beta-blocker dose. This mechanism, though occurring in a relative minority of patients, is consistent with the beneficial effects on outcome of carvedilol, compared to metoprolol tartrate.

\subsection{Limitations of the study}

The present study is a retrospective post-hoc analysis of the patients who had a HF hospitalisation in COMET. In a non-randomised analysis it is not possible with certainty to distinguish between the effects of reducing beta-blockade and the reasons for which the beta-blocker was discontinued or the dose reduced. We adjusted for available variables that are markers for disease severity, but this adjustment may be incomplete. Lastly, no data regarding the clinical course and treatment during the HF hospitalisation were collected in COMET. This hinders any inference regarding the possible effects of in-hospital treatment on subsequent outcome.

\section{Conclusions}

We have analysed the relationship between the changes in beta-blocker dose and outcome of the HF patients studied in COMET. Hospitalisations for HF were associated with a high mortality. The patients who were withdrawn from betablocker therapy or who had a dose reduction had a higher mortality compared with those who had their dose unchanged, independent of prognostic variables assessed at baseline and at the visit before hospitalisation.

\section{References}

[1] Packer M, Bristow MR, Cohn JN, et al. The effect of carvedilol on morbidity and mortality in patients with chronic heart failure. U.S. Carvedilol Heart Failure Study Group. N Engl J Med 1996;334:1349-55.

[2] Packer M, Coats AJ, Fowler MB, et al. Effect of carvedilol on survival in severe chronic heart failure. N Engl J Med 2001;344: 1651-8.

[3] MERIT-CHF Study Group. Effect of metoprolol CR/XL in chronic heart failure: metoprolol $\mathrm{CR} / \mathrm{XL}$ randomised intervention trial in congestive heart failure (MERIT-CHF). Lancet 1999;353:2001-7.

[4] CIBIS-II Investigators and Committees. The cardiac insufficiency bisoprolol study II (CIBIS-II): a randomised trial. Lancet 1999;353: 9-13.

[5] Swedberg K, Cleland J, Dargie H, et al. Guidelines for the diagnosis and treatment of chronic heart failure: executive summary (update 2005): the task force for the diagnosis and treatment of chronic heart failure of the European Society of Cardiology. Eur Heart J 2005;26:1115-40.
[6] Hunt SA, Abraham WT, Chin MH, et al. ACC/AHA 2005 guideline update for the diagnosis and management of chronic heart failure in the adult-summary article a report of the American College of Cardiology/American Heart Association Task Force on Practice Guidelines (Writing Committee to Update the 2001 Guidelines for the Evaluation and Management of Heart Failure). J Am Coll Cardiol 2005;46:1116-43.

[7] Macdonald PS, Keogh AM, Aboyoun CL, Lund M, Amor R, McCaffrey DJ. Tolerability and efficacy of carvedilol in patients with New York Heart Association class IV heart failure. J Am Coll Cardiol 1999;33:924-31.

[8] Krum H, Ninio D, MacDonald P. Baseline predictors of tolerability to carvedilol in patients with chronic heart failure. Heart 2000;84:615-9.

[9] Gardner RS, Martin W, Carter R, McDonagh TA. Importance of beta blockade in the treatment of advanced heart failure. Heart 2003;89:1442-4.

[10] Metra M, Nardi M, Giubbini R, Dei Cas L. Effects of short- and long-term carvedilol administration on rest and exercise hemodynamic variables, exercise capacity and clinical conditions in patients with idiopathic dilated cardiomyopathy. J Am Coll Cardiol 1994;24:1678-87.

[11] Kukin L, Mannino MM, Freudenberger RS, Kalman J, BuchholzVarley C, Ocampo O. Hemodynamic comparison of twice daily metoprolol tartrate with once daily metoprolol succinate in congestive heart failure. J Am Coll Cardiol 2000;35:45-50.

[12] Krum H, Roecker EB, Mohacsi P, et al. Effects of initiating carvedilol in patients with severe chronic heart failure: results from the COPERNICUS Study. JAMA 2003;289:712-8.

[13] Erdmann E, Lechat P, Verkenne P, Wiemann H. Results from post-hoc analyses of the CIBIS II trial: effect of bisoprolol in high-risk patient groups with chronic heart failure. Eur J Heart Fail 2001;3:469-79.

[14] Goldstein S, Fagerberg B, Hjalmarson A, et al. Metoprolol controlled release/extended release in patients with severe heart failure: analysis of the experience in the MERIT-HF study. J Am Coll Cardiol 2001;38:932-8.

[15] Bouzamondo A, Hulot JS, Sanchez P, Lechat P. Beta-blocker benefit according to severity of heart failure. Eur J Heart Fail 2003;5:281-9.

[16] Poole-Wilson PA, Swedberg K, Cleland JG, et al. Comparison of carvedilol and metoprolol on clinical outcomes in patients with chronic heart failure in the Carvedilol or Metoprolol European Trial (COMET): randomised controlled trial. Lancet 2003;362:7-13.

[17] Poole-Wilson PA, Cleland JG, Di Lenarda A, et al. Rationale and design of the carvedilol or metoprolol tartrate European trial in patients with chronic heart failure: COMET. Eur J Heart Fail 2002;4:321-9.

[18] Torp-Pedersen C, Poole-Wilson PA, Swedberg K, et al. Effects of metoprolol and carvedilol on cause-specific mortality and morbidity in patients with chronic heart failure-COMET. Am Heart J 2005; 149:370-6.

[19] Metra M, Torp-Pedersen C, Swedberg K, et al. Influence of heart rate, blood pressure, and beta-blocker dose on outcome and the differences in outcome between carvedilol and metoprolol tartrate in patients with chronic heart failure: results from the COMET trial. Eur Heart J 2005;26:2259-68.

[20] Komajda M, Lapuerta P, Hermans N, et al. Adherence to guidelines is a predictor of outcome in chronic heart failure: the MAHLER survey. Eur Heart J 2005;26:1653-9.

[21] Wikstrand J, Hjalmarson A, Waagstein F, et al. Dose of metoprolol tartrate $\mathrm{CR} / \mathrm{XL}$ and clinical outcomes in patients with heart failure: analysis of the experience in metoprolol tartrate $\mathrm{CR} / \mathrm{XL}$ randomized intervention trial in chronic heart failure (MERIT-CHF). J Am Coll Cardiol 2002;40:491-8.

[22] Simon T, Mary-Krause M, Funck-Brentano C, Lechat P, Jaillon P. Bisoprolol dose-response relationship in patients with congestive heart failure: a subgroup analysis in the cardiac insufficiency bisoprolol study (CIBIS II). Eur Heart J 2003;24:552-9.

[23] Parameswaran AC, Tang WH, Francis GS, Gupta R, Young JB. Why do patients fail to receive beta-blockers for chronic heart failure over time? A "real-world" single-center, 2-year follow-up experience of 
beta-blocker therapy in patients with chronic heart failure. Am Heart J 2005;149:921-6.

[24] Butler J, Khadim G, Belue R, et al. Tolerability to beta-blocker therapy among heart failure patients in clinical practice. J Card Fail 2003;9:203-9.

[25] Gattis WA, O’Connor CM, Leimberger JD, Felker GM, Adams KF, Gheorghiade M. Clinical outcomes in patients on beta-blocker therapy admitted with worsening chronic heart failure. Am J Cardiol 2003;91:169-74.
[26] Butler J, Young JB, Abraham WT, et al. Beta-blocker use and outcomes among hospitalized heart failure patients. J Am Coll Cardiol 2006;47:2462-9.

[27] Fonarow GC, Abraham WT, Albert NM, et al. Carvedilol use at discharge in patients hospitalized for heart failure is associated with improved survival: an analysis from Organized Program to Initiate Lifesaving Treatment in Hospitalized patients with Heart Failure (OPTIMIZE-HF). Am Heart J 2007;153:82e1-82e11. 